\title{
The Analysis of The Incidence of Depression and Risk of Suicide Using Buddy App on Teenagers in Makassar
}

\author{
Mutmainnah Sari ${ }^{1}$, Arbianingsih ${ }^{2}$, A. Adriana Amal ${ }^{3}$ \\ ${ }^{1}$ Nurse, Department Faculty of Medicine and Health Sciences, Alauddin State Islamic University, Makassar, \\ 2 Pediatric Nurse, Department Faculty of Medicine and Health Sciences, Alauddin State Islamic University, Makassar, \\ ${ }^{3}$ Nursing Management, Department Faculty of Medicine and Health Sciences, Alauddin State Islamic University \\ Makassar.
}

mutmainnahsarisari@gmailcom

DOI: http://doi.org/10.29080/jhsp.v3i3S.286

\begin{tabular}{l}
\hline Keywords \\
\hline Depression; \\
Early adolescence Late; \\
Adolescence Suicide risk; \\
Buddy app.
\end{tabular}

\section{Introduction}

Suicide is one of the effects of mental disorders that becomes a global spotlight today. It is supported by the many phenomena of suicide in various regions of the world. Data from the World Health Organization (WHO) in 2017 states that every year, as many as 800,000 people die due to suicide or every 40 seconds, there is one person who dies due to suicide [1]. The global suicide burden of $78 \%$ is in low and middle-income countries. Indonesia, as one of the middle-income countries, has a suicidal rate which tends to increase. Based on the WHO report in 2015, the suicide rate in Indonesia is around 4.5\% of 100,000 population [2]. In 2012, the suicide rate in Indonesia was around 4.3\% of 100,000 population.

It means there are around 9105 suicide cases each year, with 5206 women and 3900 men [3]. Suicide sometimes occurs among teenagers and becomes an important concern in various countries. Data from WHO in 2017 about the suicidal behavior of Indonesian teenagers aged 13-17 years as many as 3.9\% of teenagers in Indonesia have tried to suicide at least once in the past year, 5.6\% of teenagers have made plans about the way they do suicide, and $5.4 \%$ of teenagers are takens seriously have considered/had the idea to suicide [4]. This number really affects the quality of Indonesian teenagers in the future. Depressed teenagers are 12 times more likely to commit suicide than those who are not depressed [5]. Mental health disorders such as depression in early adolescence are often undiagnosed and untreated, especially in developing countries, due to limited access to psychological and psychiatric services and the substantial social stigma inherent in mental health problems [4]. In addition, this sensitive issue is rarely handled in the schools and families.

Makassar City, as the fourth largest city in Indonesia, has a high number of school-age adolescents. One of the interesting districts in the city of Makassar is Tamalate district which is a marginal area (suburb) and some of its areas are still classified as lagging. Tamalate is a district with a high level of poverty which is 
characterized by its position as the first rank region with the highest number of poor families who receive poor rice in Makassar City [6]. Also, the percentage of underprivileged families in Tamalate district reaches $45 \%$ (highest score) [7]. This is in line with the fact that $75 \%$ of cases occur in low and middle-income countries (LMICs) with high poverty rates. The proof shows that there is a relationship between economic variables and suicidal behavior[8]. Besides the level of poverty, Tamalate district is also classified as having the highest number of school-aged adolescents with the third highest ranking in Makassar City [7].

Based on the description above, the purpose of this study is to determine the analysis of depression incidence and suicide risk using Buddy App for teenagers in Makassar City.

\section{Methods}

This study employed a quantitative approach with descriptive-analytical cross-sectional design. The population in this study was teenagers at Junior High School and Senior High School in Tamalate District. The total population in this study was 7.557 students, determination of sample size was taken based on determining the sample size of the WHO health study through software published by John Wiley \& Sons (2000). The formula used is the formula for determining survey samples by simple random sampling, sample as many as 285 people[9].

Inclusion criteria is plural already include (1) Willing to participate in research; (2) Teenagers aged 13-18 years; (3) Teenagers who are pursuing education at Junior High Schools and Senior High Schools. Furthermore, The exclusion criteria are: (1) Teenagers with visual impairments; (2) Teenagers who have cognitive impairments.

The sampling technique used in this research was probability sampling in the form of simple random sampling to determine the school that will be the target of the research by determining the sample through the lottery. There were 3 schools selected, two junior high schools and one senior high school. A simple random sampling proportional technique is used to determine the number of respondents in each school. Teenagers at the junior high school are 189 people and teenagers at senior high school are 96 people.

This research is conducted by using Buddy App and online form. Buddy is based on the English dictionary, meaning good friends. The Buddy app name is given because of its function as an application that can be a close friend to the user. Buddy app is an android based application that contains suicide detection questions adopted from Columbia Suicide Severity Rating Scale (CSSRS) which is a question with the triage method [10]. CSSRS consists of 6 key questions with 2 types of answer options (yes/no) that will detect the risk of teenagers suicide based on the priority color of the question. The results of detection of suicide risk are as follows: high risk, medium risk, low risk, and very low risk. This instrument has previously been tested for its validity and reliability in Indonesia by Jeli Pratiwi, a Bachelor of Psychology, Semarang State University with the title Suicide Ideation on Teenagers in Semarang City [11]. While, the online form contains questions related to depression screening of users, by using the Kutcher Adolescent Depression Scale (KADS) instrument which has been tested for validity and reliability as well.

The Data analysis in this study used bivariate analysis. Bivariate analysis is used to identify the difference of the two variable either it is significant not. The test used was the chi-square test and Kolmogorov-smirnov alternative test, with a confidence interval 95\% with a significance level 5\% ( $\alpha=$ 0.05). If the result is $\mathrm{p} \leq \alpha$, so there is a meaningful difference between the two variables.

This research has also been reviewed by health research ethics committee meeting in Medical and Health Science Faculty, Alauddin State Islamic University of Makassar, with a number. A.007 / KPEPK / FKIK / VIII / 2018.

\section{Results}

Statistical test results show that there are significant differences between the incidence of depression in early teenagers and late teenagers with a p-value $0,000(p<0.05)$. The percentage of depression cases compared with those who are not depressed is more prevalent and occured in late teenagers with a percentage $63,6 \%$ while the depression incidence compared with those who are not depressed in early teenagers is only around $37.1 \%$.

Table 1. Frequency Distribution of Depression Events Based on Teenagers Development Period in Tamalate District $(n=285)$

\begin{tabular}{|c|c|c|c|c|c|}
\hline \multirow[t]{3}{*}{ Depression Incidence } & \multicolumn{4}{|c|}{ Development Period } & \multirow[t]{3}{*}{$P$ Value } \\
\hline & \multicolumn{2}{|c|}{$\begin{array}{c}\text { Early } \\
\text { Teenager }\end{array}$} & \multicolumn{2}{|c|}{ Late Teenager } & \\
\hline & $\mathrm{n}$ & $\%$ & $\mathrm{n}$ & $\%$ & \\
\hline Depressed & 62 & 37.1 & 75 & 63.6 & \multirow{3}{*}{0.000} \\
\hline Not Depressed & 105 & 62.9 & 43 & 36.4 & \\
\hline Total & 167 & 100 & 118 & 100 & \\
\hline Chi-Squre Test & & & & & \\
\hline
\end{tabular}


Description of the level of suicide risk based on the teenagers' development period

Statistical test results show that there are significant differences between the level of suicide risk in early teenagers and late teenagers with a p-value $0.022(p<0.05)$. The percentage of suicide risk from low to high category is more prevalent or occurred in late teenagers with percentage $39 \%$ per 118 population compared to early teenagers who have only $21 \%$ per 167 population. There are at least 6 teenagers who have previously attempted or tried to commit suicide.

Table 2. Frequency Distribution of Suicide Risk Based on Teenagers Development Period in Tamalate District ( $\mathrm{n}=285$ )

Level Of Suicide Risk

\begin{tabular}{|c|c|c|}
\hline \multicolumn{2}{|c|}{ Development Period } & \multirow{2}{*}{ p-value } \\
\hline Early Teenager & Late Teenager & \\
\hline
\end{tabular}

\begin{tabular}{|c|c|c|c|c|c|}
\hline Very Low Risk & 132 & 79.0 & 72 & 61.0 & \multirow{5}{*}{0.022} \\
\hline Low Risk & 24 & 14.4 & 31 & 26.3 & \\
\hline Medium Risk & 5 & 3.0 & 9 & 7.6 & \\
\hline High Risk & 6 & 3.6 & 6 & 5.1 & \\
\hline Total & 167 & 100 & 118 & 100 & \\
\hline
\end{tabular}

Kolmogorov-Smirnov Test

Analysis of depression incidence and the suicide risk of teenagers in Tamalate District

Statistical test results show that there are significant differences between the level of suicide risk in people who are depressed and not depressed with a p-value $0.000(p<0.05)$. From the data obtained that from 137 teenagers who experience depression 72 (55\%) of them have an idea to suicide. There are 12 $(8.8 \%)$ teenagers of who have a high risk to do suicide, with 6 of them have done suicide attempts previously. In addition, out of 148 teenagers who are not depressed, there are 9 teenagers who have low risk to do suicide (have the idea of suicide).

Table 3. Analysis of Depression and Teenager Suicide Risks in Tamalate District ( $\mathrm{n}=285)$

\begin{tabular}{lcrrrr}
\hline \multirow{2}{*}{ Level Of Suicide Risk } & \multicolumn{3}{c}{ Depression Incidence } & P Value \\
\cline { 2 - 5 } & \multicolumn{2}{c}{ Depressed } & Not Depressed & \\
\cline { 2 - 5 } & $\mathrm{n}$ & $\%$ & $\mathrm{n}$ & $\%$ \\
\hline Very Low Risk & 65 & 47.4 & 139 & 93.9 \\
\hline Low Risk & 46 & 33.6 & 9 & 6.1 \\
\hline Medium Risk & 14 & 10.2 & 0 & 0.0 \\
\hline High Risk & 12 & 8.8 & 0 & 0.0 & 0.000 \\
\hline \multicolumn{1}{l}{ Total } & 137 & 100 & 148 & 100 \\
\hline
\end{tabular}

Kolmogorov-Smirnov Test

Analysis of depression incidence and the suicide risk of early teenagers in Tamalate District

Statistical test results show that there are significant differences between the level of suicide risk in early teenagers who are depressed and not depressed with a p-value of $0.000(p<0.05)$. From the data obtained that from 62 early teenagers who experience depression, 28 (45.2\%) of them have an idea to do suicide. Furthermore, there are $6(9.7 \%)$ teenagers who have a high risk of suicide, with 4 of them have done suicide attempts previously.

Table 4. Analysis of Depression Incidence and The Level of Suicide Risk of Early Teenagers in Tamalate District $(\mathrm{n}=167)$

\begin{tabular}{|c|c|c|c|c|c|c|c|}
\hline \multirow[t]{3}{*}{ Level Of Suicide Risk } & \multicolumn{4}{|c|}{ Depression Incidence } & \multirow{2}{*}{\multicolumn{2}{|c|}{ Total }} & \multirow[t]{3}{*}{ P Value } \\
\hline & \multicolumn{2}{|c|}{ Depressed } & \multicolumn{2}{|c|}{ Not Depressed } & & & \\
\hline & $\mathrm{n}$ & $\%$ & $\mathrm{n}$ & $\%$ & $\mathrm{n}$ & $\%$ & \\
\hline Very Low Risk & 34 & 54.8 & 98 & 93.3 & 132 & 79.0 & \multirow{5}{*}{0.000} \\
\hline Low Risk & 17 & 27.4 & 7 & 6.7 & 24 & 14.4 & \\
\hline Medium Risk & 5 & 8.1 & 0 & 0.0 & 5 & 3.0 & \\
\hline High Risk & 6 & 9.7 & 0 & 0.0 & 6 & 3.6 & \\
\hline Total & & & & & 167 & 100 & \\
\hline
\end{tabular}

Kolmogorov-Smirnov Test

Analysis of depression incidence and the suicide risk of late teenagers in Tamalate District 
Statistical test results show that there are significant differences between the level of suicide risk in late teenagers who are depressed and not depressed with a p-value of $0.000(p<0.05)$. From the data obtained that from 75 late teenagers who are depressed 44 (58.7\%) of them have an idea to do suicide. Furthermore, there are $6(8.0 \%)$ teenagers who have a high risk of suicide, with 2 of them have done suicide attempts previously.

Table 5. Analysis of Depression Incidence and The Level of Suicide Risk of Late Teenagers in Tamalate District $(n=118)$

\begin{tabular}{|c|c|c|c|c|c|c|c|}
\hline \multirow[t]{3}{*}{ Level Of Suicide Risk } & \multicolumn{4}{|c|}{ Depression Incidence } & \multirow{2}{*}{\multicolumn{2}{|c|}{ Total }} & \multirow[t]{3}{*}{ P Value } \\
\hline & \multicolumn{2}{|c|}{ Depressed } & \multicolumn{2}{|c|}{ Not Depressed } & & & \\
\hline & $\mathrm{n}$ & $\%$ & $\mathrm{~N}$ & $\%$ & $\mathrm{n}$ & $\%$ & \\
\hline Very Low Risk & 31 & 41.3 & 41 & 95.3 & 72 & 61.0 & \multirow{5}{*}{0.000} \\
\hline Low Risk & 29 & 38.7 & 2 & 4.7 & 31 & 26.3 & \\
\hline Medium Risk & 9 & 12.0 & 0 & 0.0 & 9 & 7.6 & \\
\hline High Risk & 6 & 8.0 & 0 & 0.0 & 6 & 5.1 & \\
\hline Total & & & & & 118 & 100 & \\
\hline
\end{tabular}

Kolmogorov-Smirnov Test

\section{Discussion}

Youth is a period of great change for all young people and can pose a variety of physical, social, emotional, and academic challenges. This stage is the time for young people to build their identity, seek greater independence, stages of transition to adulthood, and often face pressure from the school, and the social environment. This stage is also the peak age of onset of many mental health disorders [12].

During the research process, early teenagers tend to be brave to convey their problems and have greater openness than late teenagers who tend to be difficult to convey their problems. This is because late teenagers begin to have the of thinking and begin to be able to make their own decisions based on their identity. The ability to make decisions and increasingly critical thinking makes late teenagers tend to save their own problems.

Lawrence et al (2015) explain that the prevalence of major depression will be higher occurs in the older group [13]. The high incidence of depression in late teenagers are caused the growing of responsibility that they should fight for, whether the responsibility of parents, the teacher and the people who are to them. Many of teenagers are respondents required to succeed in academic achievement, especially at Senior High School which is required to enter the best campus after graduating.

Academic stress can play an important role in determining adolescent mental health [14]. Stress due to education, anxiety, and depression affect students' QOL (quality of life) which has an impact on teenager mental health. Stress is a major risk factor of depression and mostly occurs in late teenagers [15]. At the final stage of the teenager, they are mature of thinking, but problems in this stage will also increase. Higher levels of education will also demand more rigorous academic activities.

In this research, early teenagers tend to have problems with relationships of the opposite sex, bullying, substance abuse and problems with parents who are too busy with their job, and some even have parents who have been separated or divorced so they have to bear the burden. While late teenagers tend to have more complex problems, in terms of relationships with the opposite sex (romance), high academic stress, demands greater responsibility, substance abuse problems, divorced parents, the pressure of the family, family violence and relationships who cracks with someone (parting with the closest person).

The level of suicide risk in this research has 4 levels, including high, medium, low, and very low risk. The focus of this research is teenagers who have suicidal ideas and suicidal behavior. Someone is called have a suicide idea or ever thought of committing suicide if at least included in category of low to high risk of suicide. Whereas teenagers are called have no idea of suicide or never thought of committing suicide if they fall into the category of very low risk of suicide.

The high of suicide idea is thought to be due to burden of problems experienced by older teenagers is greater than those who are younger (early teenagers) [11]. Asante et al (2017) state that the risk of suicide will increase at a higher age level. The percentage of suicidal ideas, suicide plans, and suicide attempts have a high percentage at the age of 17 and after 18 years old [16]. In this research, late teenagers tend to commit suicide because the incidence of depression in late teenagers is also high. Depression is a major cause of suicide risk in teenagers. In addition, the problem of late teenagers is more complicated, if they do not have a good copying mechanism, depression will end in suicidal behavior.

Teenagers who are faced with a problem without realizing will cross their minds about the desire to die in order to end the pain and suffering they experience. After the desire to die arises, finally, it starts to cross their minds about how they try and commit suicide, until finally their suffering is avenged by suicide[11]. In early teenager, the ability to reason and make decisions is still difficult. They are still unstable and experience an identity crisis, so the role of parents and teachers of this stage is very much 
needed. Late teenagers tend to be able to think critically and make their own decisions, but the stage of development still need more help when facing problems. Decisions taken tend to be aggressive and sometimes still falter. Therefore, people who are trusted are very important for them to alleviate the problem.

During the process of this research, some teenagers ventured to consult with researchers regarding problems faced, many of them experienced stress in academic matters, family problems, love problems, problems with friends, substance use (smoking, alcohol and drugs). The majority of teenagers dare to say that they are "depressed". Although it is known that depression is a common condition, the effects of depression should not be ignored.

An early teenager is initial stage of puberty initiation, the regulatory system is still in an immature stage so it tends to have overflowing emotions [17]. The frontal lobe, which is part of the brain that regulates reasoning and decision making, begins to develop during early teenager. The frontal lobe is still in the early stages of development causing their tendency to act impulsively and not critically in thought [18]. This caused some of them desperate to commit suicide attempts, because emotions are overwhelming and immature of making decisions.

Early teenagers who depressed in this research predominantly have problems in terms of romance, bullying, problems with parents (divorced parents, parents less concerned and too busy with work), substance abuse problems and separation from the closest person. This long-standing and intense problem will have an impact on the idea of suicide, only starting from just thinking about suicide and eventually leading to suicide attempts. Personal problems related to the situation above will have an impact on the inaccessibility of the tasks of teenager development in this period. It will have an impact on its development at the next stage.

When compared with the prevalence of depression and suicide risk in early teenagers, the late teenager has a higher prevalence. This is because at this time the responsibilities and expectations or expectations of something will be even greater. The problems faced by late teenagers also will be more numerous and diverse, for example in terms of academics, problems of romance (at this stage, teenagers begin to be more serious with the opposite sex), family problems, and various other problems.

At this time, a teenager is not only reactive but also begins to actively achieve activities to find their identity, look for life guidelines for the provision of their life in the future. Activities carried out by teenagers at this stage are carried out with passion and enthusiasm, but teenager do not yet understand the nature of something they are looking for [19]. At the stage of late teenager, emotions that are not yet stable enough, the self-regulation system that continues to develop makes this age stage sometimes still has a changing emotional status between behaviors that show maturity and behavior like children [17].

The problem is more complex in late teenager led to the prevalence of depression and suicide risk is higher in this age. However, at this stage, the development and physical growth will continue, including the frontal lobe which is part of the brain that regulates reasoning and decision making. The frontal lobe that undergoes further development causes late teenagers that begin to tend to have reasoning abilities and the ability to make their own decisions well [17]. This is the reason for more attempted suicide the early teenager, because the ability of reasoning power is still in the early stages of development, whereas in teenager is the end of the reasoning power to start working. However, reasoning ability also will not function if the problems faced are far greater and more complex. Therefore, the ability of the coping mechanism must be strong at this age.

\section{Conclusion and Suggestion}

The incidence of depression and the level of suicide risk have a greater percentage in late teenagers. Analysis of depression incidence and suicide risk is found, from 137 teenagers who are depressed as many as $72(53 \%)$ teenagers including suicidal ideas with 12 of them have a high risk, 6 of them have done suicide attempts previously

\section{References}

1. WHO. Suicide: Key Facts [Internet]. 2017. Available from: http://www.who.int/mediacentre/factsheets/fs398/en/

2. WHO Region. Global Health Observatory data repository [Internet]. 2017. Available from:http://apps.who.int/gho/data/?theme=main

3. WHO. Preventing Suicide: A Global Imperative [Internet]. 2014. Available from: http://apps.who.int/iris/bitstream/10665/131056/1/9789241564779_eng.pdf

4. WHO SEARO. Mental Health Status of Adolescents in South-East Asia : Evidence for Action. WHO Regional Office for South-East Asia; 2017.

5. King KA, Vidourek RA. Teen Depression and Suicide: Effective Prevention and 
Intervention Strategies. Prev Res. 2012;19(4):15-8.

6. BPS Kota Makassar. Makassar dalam Angka 2015 [Internet]. Indonesia; 2015. Available from: https://makassarkota.bps.go.id/publication/2015/12/07/8a96de1a071d6cfe4ea418e1/keca matan-makassar-dalam-angka-2015.html

7. BPS Kota Makassar. Kecamatan Tamalate dalam Angka 2017 [Internet]. Makassar; 2017. Available from: https://makassarkota.bps.go.id/

8. Bantjes J, Lemmi V, Coast E, Channer K, Leone T, McDaid D, et al. Poverty and Suicide Research in Low- and Middle-Income Countries: Systematic Mapping of Literature Published in English and A Proposed Research Agenda. Glob Ment Heal [Internet]. $2016 ; 3$. Available from: https://www.ncbi.nlm.nih.gov/pmc/articles/PMC5454768/pdf/S2054425116000273a.pdf

9. Wiley J, Sons. Rumus Sample Survey. World Health Organization; 2000.

10. Posner K, Brent D, Lucas C, Gould M, Stanley B, Brown G, et al. Columbia Suicide Severity Rating Scale (C-SSRS). Columbia: The Research Foundation for Mental Hygiene; 2008. p. 1-3.

11. Pratiwi J, Undarwati A. Suicide Ideation pada Remaja di Kota Semarang. Dev Clin Psychol. 2014;3(1):24-34.

12. Yeomans C, Christensen H. Youth Mental Health Report [Internet]. Australia; 2016. Available from: https://blackdoginstitute.org.au/docs/default-source/research/evidenceand-policy-section/2017-youth-mental-health-report_mission-australia-and-black-doginstitute.pdf?sfvrsn=6

13. Lawrence D, Johnson S, Hafekost J, Haan KB de, Sawyer M, Ainley J, et al. The Mental Health of Children and Adolescents [Internet]. Australia; 2015. Available from: https://www.health.gov.au/internet/main/publishing.nsf/Content/9DA8CA21306FE6EDC A257E2700016945/\$File/child2.pdf

14. Subramani, Kadhiravan. Academic Stress and Mental Health Among High School Students Academic Stress and Mental Health Among High School Students. Indian J Appl Res [Internet]. 2017;7(5):2-5. Available from: https://www.researchgate.net/publication/321572693 Academic Stress and Mental Health Among High School Students

15. Assana S, Laohasiriwong W, Rangseekajee P. Quality of Life , Mental Health and Educational Stress of High School Students in the Northeast of Thailand. J Clin Diagnostic Res [Internet]. 2017;11(8):1-6. Available from: https://www.ncbi.nlm.nih.gov/pmc/articles/PMC5620889/pdf/jcdr-11-VC01.pdf

16. Oppong K, Kugbey N, Osafo J, Quarshie EN, Owusu J. SSM - Population Health The prevalence and correlates of suicidal behaviours (ideation , plan and attempt) among adolescents in senior high school in Ghana. SSM - Popul Heal [Internet]. 017;3 (February):427-34. Available from: http://dx.doi.org/10.1016/j.ssmph.2017.05.005

17. Curtis AC. Defining Adolescence. J Adolesc Fam Heal [Internet]. 2015;7(2). Available from: https://scholar.utc.edu/jafh/vol7/iss $2 / 2$

18. Unicef. Adolescence An Age of Opportunity [Internet]. 2011. Available from: https://www.unicef.org/adolescence/files/SOW_2011_Main_Report_EN_02092011.pdf

19. Pieter HZ, Lubis NL. Pengantar Psikologi Dalam Keperawatan. Jakarta: Kencana Prenada Media Grup; 2012. 